\title{
At clinically relevant concentrations the anaesthetic/amnesic thiopental but not the anticonvulsant phenobarbital interferes with hippocampal sharp wave-ripple complexes Costas Papatheodoropoulos*1, Evangelos Sotiriou ${ }^{1,2}$, Dimitrios Kotzadimitriou ${ }^{1}$ and Panagiota Drimala ${ }^{1,3}$
}

Address: ${ }^{1}$ Department of Physiology, Medical School, University of Patras, Rion, Greece, ${ }^{2}$ Division of Basic Neurosciences, Foundation for Biomedical Research of the Academy of Athens (IIBEAA), Athens, Greece and ${ }^{3}$ Central and North West London Mental Health NHS Trust, Substance Misuse Service, 5-7 Wolverton Gardens, London, W6 7DY, UK

Email: Costas Papatheodoropoulos* - cepapath@med.upatras.gr; Evangelos Sotiriou - esotir@bioacademy.gr; Dimitrios Kotzadimitriou - dikotzadim@upatras.gr; Panagiota Drimala - drimala@nucleus.med.upatras.gr

* Corresponding author

\section{Published: 31 July 2007}

BMC Neuroscience 2007, 8:60 doi:10.1 |86/147|-2202-8-60
Received: 13 March 2007

Accepted: 3I July 2007

This article is available from: http://www.biomedcentral.com/I47I-2202/8/60

(C) 2007 Papatheodoropoulos et al; licensee BioMed Central Ltd.

This is an Open Access article distributed under the terms of the Creative Commons Attribution License (http://creativecommons.org/licenses/by/2.0), which permits unrestricted use, distribution, and reproduction in any medium, provided the original work is properly cited.

\begin{abstract}
Background: Many sedative agents, including anesthetics, produce explicit memory impairment by largely unknown mechanisms. Sharp-wave ripple (SPW-R) complexes are network activity thought to represent the neuronal substrate for information transfer from the hippocampal to neocortical circuits, contributing to the explicit memory consolidation. In this study we examined and compared the actions of two barbiturates with distinct amnesic actions, the general anesthetic thiopental and the anticonvulsant phenobarbital, on in vitro SPW-R activity.

Results: Using an in vitro model of SPW-R activity we found that thiopental (50-200 $\mu \mathrm{M})$ significantly and concentration-dependently reduced the incidence of SPW-R events (it increased the inter-event period by $70-430 \%$ ). At the concentration of $25 \mu \mathrm{M}$, which clinically produces mild sedation and explicit memory impairment, thiopental significantly reduced the quantity of ripple oscillation (it reduced the number of ripples and the duration of ripple episodes by $20 \pm 5 \%, n=12, P<0.01$ ), and suppressed the rhythmicity of SPWs by $43 \pm 15 \%(n=6, P<0.05)$. The drug disrupted the synchrony of SPWs within the CAI region at $50 \mu \mathrm{M}$ (by $19 \pm 12 \% ; n=5, P<0.05$ ). Similar effects of thiopental were observed at higher concentrations. Thiopental did not affect the frequency of ripple oscillation at any of the concentrations tested $(10-200 \mu \mathrm{M})$. Furthermore, the drug significantly prolonged single SPWs at concentrations $\geq 50 \mu \mathrm{M}$ (it increased the half-width and the duration of SPWs by 35-90\%). Thiopental did not affect evoked excitatory synaptic potentials and its results on SPW-R complexes were also observed under blockade of NMDA receptors. Phenobarbital significantly accelerated SPWs at 50 and $100 \mu M$ whereas it reduced their rate at 200 and $400 \mu \mathrm{M}$. Furthermore, it significantly prolonged SPWs, reduced their synchrony and reduced the quantity of ripples only at the clinically very high concentration of $400 \mu \mathrm{M}$, reported to affect memory.

Conclusion: We hypothesize that thiopental, by interfering with SPW-R activity, through enhancement of the $\mathrm{GABA}_{\mathrm{A}}$ receptor-mediated transmission, affects memory processes which involve hippocampal circuit activation. The quantity but not the frequency of ripple oscillation was affected by the drug.
\end{abstract}




\section{Background}

Sedative drugs, including barbiturates, induce episodic memory impairment in humans [1-4] through poorly understood mechanisms. The hippocampus appears to be a key structure in episodic memory processing [5-7]. Timely structured activity of cell assemblies is thought to underlie encoding and transient storage of explicit memory traces in the hippocampal circuit [8]. These memory traces are reactivated during subsequent behavioral stages [9-11] namely during bursts of activity called sharp waveripple complexes (SPW-R) consisting of a relatively slow wave (sharp wave; [12-14] crowned by high frequency oscillation (ripple, 100-200 Hz; [13,15-17]. SPW-R activity occurs mainly during slow wave sleep and awake immobility $[13,18]$, and it is also observed in high temporal proximity to the experienced event [19]. Studies showing temporal correlation between SPW-R and neocortical activity $[17,20,21]$ suggest that SPW-R constitute the neuronal substrate for information transfer in the hippocampo-neocortical circuits [22], contributing to the longterm storage of short-term memories and thus to memory consolidation in neocortical circuits $[17,23,24]$. The study of the effects of amnesia-inducing agents on hippocampal SPW-R activity becomes increasingly interesting in light of the above research evidence.

In vitro experimentation continuously provides new data demonstrating the great impact of isolated preparations as models in elucidating the mechanisms underlying brain rhythms and the action of centrally acting drugs on these rhythms $[25,26]$. In particular, slice preparation offers unique advantages of experimental control for studying the network mechanisms underlying distinct and isolated elements of cooperative population activities. In vitro models of SPW-R activity have recently been developed using hippocampal preparations [27-31]. In vitro SPW-R activity presents certain experimental advantages including its spontaneous generation in hippocampal slices under standard conditions without being induced by pharmacological agents or other experimental manipulation. Thus, it is especially suitable for pharmacological examinations since complex drug interactions which could interfere with the mechanisms underlying the effects of the drug under investigation are avoided.

Using the in vitro SPW-R we studied the effects of two barbiturates, thiopental and phenobarbital, which have different clinical usage and display distinct effects on memory processes. Thiopental, one of the most commonly used barbiturates, is an intravenously used general anesthetic, producing anterograde amnesia [32-34]. It preferentially affects explicit memory [1,35]. General anesthetics apparently affect the transition from shortterm to long-term storage of explicit memories [36]. On the other hand, the anticonvulsant phenobarbital shows less consistent effects on memory processes. Some studies revealed no detectable effects on memory $[37,38]$ while others describe memory impairment $[39,40]$ especially when doses at the high end of the therapeutic range were used $[41,42]$.

We show that at clinically relevant concentrations the two drugs differently affect SPW-R complexes, with thiopental strongly affecting activity and phenobarbital displaying no significant effects.

\section{Results}

\section{Characteristics of SPW-R activity}

Spontaneous sharp wave-ripple (SPW-R) complexes (Fig. $1 \mathrm{~A}, \mathrm{~B})$ were consistently recorded in seventy-eight ventral hippocampal slices taken from forty-eight animals. SPWs in st. pyramidale consisted of positive potentials with a mean amplitude, half-width and duration of $0.22 \pm 0.02$ $\mathrm{mV}(\mathrm{n}=74), 24.8 \pm 6.5 \mathrm{~ms}(\mathrm{n}=60)$ and $79.8 \pm 5.4 \mathrm{~ms}(\mathrm{n}$ $=60)$ respectively, and they occurred every $0.410 \pm 0.02$ $\sec (\mathrm{n}=74)$ (Fig. 1B-C,E). SPWs although not literally oscillatory, presented a certain degree of rhythmicity evident using auto-correlation analysis [31], (Fig. 1F). Ripples appeared as a high-frequency oscillation associated to the SPW slow potential and they were detected after bandpass filtering raw signal at $100-300 \mathrm{~Hz}$ (Fig. 1C). Ripple oscillation was also revealed as a clearly distinguishable peak in fast Fourier transforms (Fig. 1D). The mean values of the ripple number inside a ripple episode, the duration of ripple episode and the frequency of ripple oscillation were respectively $7.0 \pm 0.3$ ripples $(\mathrm{n}=49), 38 \pm 2 \mathrm{~ms}(\mathrm{n}$ $=49)$ and $161.0 \pm 2.5 \mathrm{~Hz}(\mathrm{n}=69)$. Multiunit activity, revealed after band-pass filtering, was associated with SPW-R events (Fig. 1C-4). Similarly to previous observations [43] the mean frequency of multiunit activity accompanying SPW-Rs ranged among slices from 75 to $420 \mathrm{~Hz}$ (mean value $232 \pm 36 \mathrm{~Hz}, \mathrm{n}=9$ slices). Most of the experiments were carried out in CA1; however, in some experiments recordings were made in CA3. Statistical comparisons (independent t-test) showed that the different measures did not significantly differ between the two fields. For instance, in CA1 the mean values of amplitude, half-width and duration of SPWs were respectively $0.21 \pm 0.02 \mathrm{mV}(\mathrm{n}=63), 25.0 \pm 1.0 \mathrm{~ms}(\mathrm{n}=46)$ and 79.0 $\pm 6.3 \mathrm{~ms}(\mathrm{n}=46)$; the corresponding values in CA3 $(\mathrm{n}=$ 11) were respectively $0.27 \pm 0.05 \mathrm{mV}, 24 \pm 1.2 \mathrm{~ms}$ and $83.0 \pm 9.9 \mathrm{~ms}$. The measures of ripples were similar between CA1 and CA3 as well, although the ripple episodes were slightly longer in CA1 than in CA3, but not significantly so. The mean values of the ripples' number, the duration of the ripple episode and the ripple frequency in CA1 $(\mathrm{n}=31)$ vs CA3 $(\mathrm{n}=8)$ were respectively $7.4 \pm 0.4$ vs $6.7 \pm 0.6$ ripples, $41.2 \pm 2.7$ vs $36.3 \mathrm{~ms}$ and $161.0 \pm 3.3 \mathrm{vs}$ $164.0 \pm 6.5 \mathrm{~Hz}$. 
A

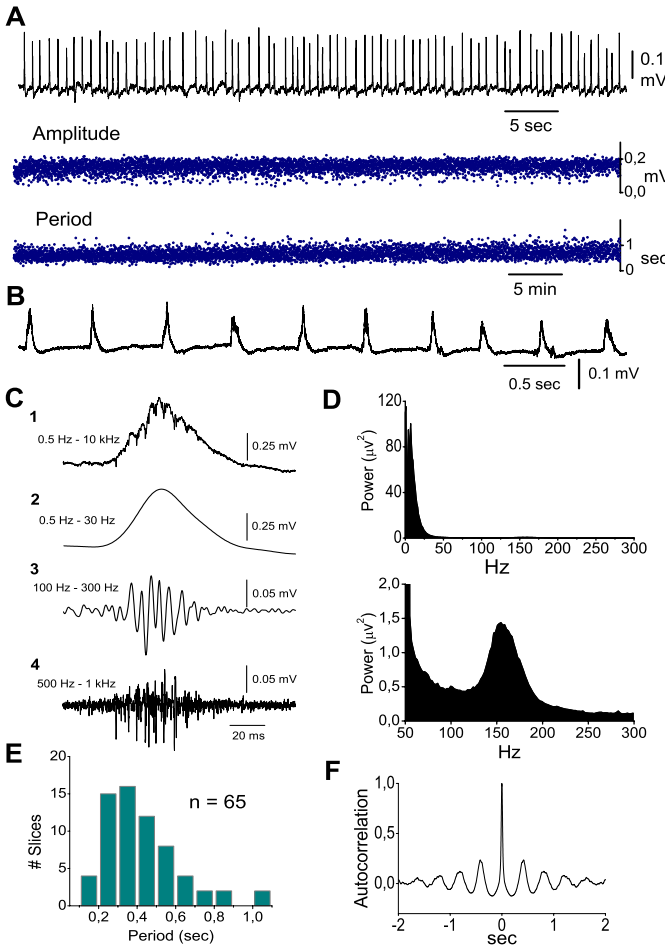

Figure I

In vitro SPW-R activity recorded in the st. pyramidale of CAI region of ventral hippocampal slices perfused with standard medium. A. Continuous long-lasting field recording of SPWs (trace on the top, low-pass filtered at $35 \mathrm{~Hz}$ ) and the corresponding time histograms of amplitude (middle) and period (bottom). Data were obtained from a slice four hours after its placement on the recording chamber. Note the persistency and stability over time of both characteristics of SPWs. B. Record of spontaneous activity obtained from a different slice, presented at a faster sweep speed. C. A wide band record of a single SPW-R event (CI) and the filtered sweeps are shown, illustrating the distinct components of the event. Low-pass $(0.5-30 \mathrm{~Hz})$ and bandpass $(100-300 \mathrm{~Hz}$ ) filtering reveals the slow wave (C2) and the associated ripple oscillation (C3) respectively. Band-pass filtering at very high frequencies $(0.5-1 \mathrm{kHz}, \mathrm{C} 4)$ discloses the burst-like multiunit activity occurring mostly during the rising and peaking phases of the slow positive potential. $\mathbf{D}$. FFT from I min raw record of spontaneous activity showing the difference in power between SPWs (upper diagram) and ripples (lower diagram, same power spectrum shown at a greater magnification). SPW dominant peak is at $5-10 \mathrm{~Hz}$. Ripple activity is at $\sim 150 \mathrm{~Hz}$. E. Histogram of period (interevent interval) of SPWs calculated from a population of slices, showing that most of the slices displayed a period between $0.2-0.6 \mathrm{sec}$, which correspond to a frequency range of I.5-5.0 Hz. F. Auto-correlogram from a $5 \mathrm{~min}$ low-pass record from a distinct experiment, showing the typical degree of rhythmicity of SPWs.
The pharmacological experiments in the present study were carried out at $32^{\circ} \mathrm{C}$, which is $4-7^{\circ} \mathrm{C}$ lower than the body temperature in the intact animal [44]. In order to examine the effects of temperature on SPWs and ripple oscillation, the temperature in the recording chamber was changed systematically while continuously recording SPW-R activity from the CA1 pyramidal layer. The temperature changes significantly affected the rate of SPWs and the ripple frequency, but not the magnitude (i.e. amplitude or power) of the events. Furthermore, SPWs and ripples were affected differently. In particular, lowering the temperature from 32 to $27^{\circ} \mathrm{C}$ significantly slowed down SPWs by $49 \pm 6 \%$ (paired t-test, $\mathrm{n}=4, P<0.01$ ) (Fig. 2). The mean rate of SPWs was not significantly changed when the temperature was increased from $32^{\circ} \mathrm{C}$ to $37^{\circ} \mathrm{C}$, as has been also previously observed [45]. However, at $37^{\circ} \mathrm{C}$ SPWs were often generated as bursts of two to four waves (Fig. 2B). The ripple frequency changed linearly with temperature, increasing monotonically when the temperature was increased from 27 to $37^{\circ} \mathrm{C}$. In particular, the ripple frequency increased by $29.4 \pm 0.7 \%$ from 27 to $32^{\circ} \mathrm{C}$ and by $38 \pm 4 \%$ from 32 to $37^{\circ} \mathrm{C}$ (Fig. $2 \mathrm{~B}, \mathrm{C}$ ). The mean value of the ripple frequency observed at $32^{\circ} \mathrm{C}(160$ $\pm 8 \mathrm{~Hz}$ ) was at the range of the ripple frequency observed in vivo (i.e. $120-200 \mathrm{~Hz}$ ) $[15,46-48]$. However, at $27^{\circ} \mathrm{C}$ and $37^{\circ} \mathrm{C}$ the values of ripple frequency $(113 \pm 6.6 \mathrm{~Hz}$ and $221 \pm 12.5 \mathrm{~Hz}$ respectively) were at the limits of the physiological range of the ripple frequency. These experiments indicated that, although certain properties of SPWRs in vitro are affected by temperature, in vitro SPW-R activity closely resembles its in vivo counterpart when slices are maintained at the temperature of $32^{\circ} \mathrm{C}$.

\section{Thiopental effects on in vitro SPW-R complexes}

Thiopental was applied in the perfusion medium at the concentrations of 10, 25, 50, 100 and $200 \mu \mathrm{M}$. Clinical concentrations of thiopental range from 10 to about 100 $\mu \mathrm{M}[1,32,35,49-51]$. Somewhat larger maximal concentrations have been reported in studies using experimental animals [52-55]. Recordings were typically performed in CA1, but in some experiments (no more than three at each concentration) recordings were made in CA3. Since no difference was found between CA1 and CA3 the measures obtained from the two fields were pooled together. Thiopental produced concentration-dependent and reversible changes in most of the characteristics of SPWs and ripples. As illustrated in Fig. 3, thiopental at concentrations $\geq 50 \mu \mathrm{M}$ significantly reduced the rate of SPWs (i.e. it increased the period between single SPWs) and prolonged single SPW (Fig. 2A \&2C), without significantly affecting the amplitude of potentials, the mean percent change of which at the five concentrations $(10,25,50100$ and $200 \mu \mathrm{M})$ was respectively $1.6 \pm 5.8 \%(\mathrm{n}=12), 0.4 \pm$ $4.3 \%(\mathrm{n}=18), 16.4 \pm 8.5 \%(\mathrm{n}=21), 13.3 \pm 12.2 \%(\mathrm{n}=$ $12)$ and $10.3 \pm 18.7 \%(n=9)$. Furthermore, the drug sig- 

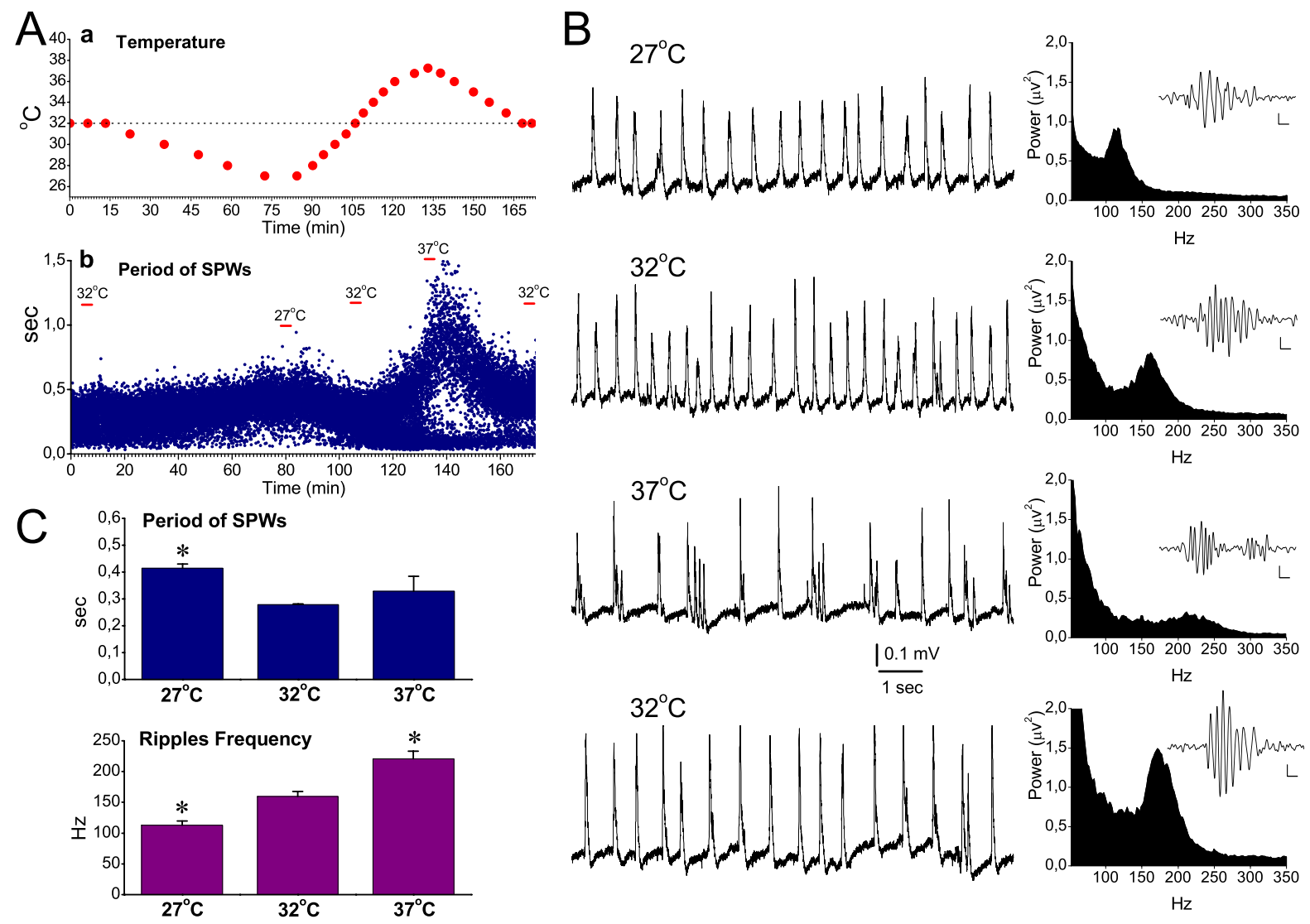

Figure 2

Effects of temperature on SPWs and ripple oscillation. A. Representative experiment showing the time course of the temperature changes (a) and the induced fluctuations in the period of SPWs recorded from the CAI pyramidal layer (b). The dotted line in "a" marks the temperature of $32^{\circ} \mathrm{C}$. In "b", the three representative temperatures $\left(32^{\circ} \mathrm{C}, 27^{\circ} \mathrm{C}\right.$ and $\left.37^{\circ} \mathrm{C}\right)$ are indicated for purpose of comparison. During the increase of the temperature from $34-35^{\circ} \mathrm{C}$ to higher values, the histogram of the period bifurcated. This deviation of the values was due to the fact that SPWs were frequently generated in a burst-like fashion (shown in B), where consecutive waves appeared at short intervals, whereas at the same time the period between bursts of events increased. B. Continuous recording of SPW-R complexes (left column) and power spectra at the high frequency range (right column) obtained at different temperatures. Single ripple episodes (band-pass filtered traces) are shown as inserts in spectral plots; calibration bars: $10 \mu \mathrm{V}, 10 \mathrm{~ms}$. At $37^{\circ} \mathrm{C}$ SPWs appeared frequently as bursts of several events. Ripple frequency changed monotonically with temperature. Note that at $37^{\circ} \mathrm{C}$ ripple frequency exceeded $200 \mathrm{~Hz}$. Data in "A" an "B" were collected from two different slices. C. Collective date of the period of SPWs and of the frequency of ripple oscillation at three different temperatures. Asterisks indicate significant differences with reference to the group of $32^{\circ} \mathrm{C}$ (paired t-test, at $P<0.05$, n $=4)$.

nificantly reduced rhythmicity of SPWs (starting at $25 \mu \mathrm{M}$; Fig. 3B) and the synchronization of SPWs across the CA1 region, as observed by the reduction in cross-correlation (Fig. 3D). At the concentrations of 100 and $200 \mu \mathrm{M}$ the drug abolished spontaneous activity in $4 / 15$ and 5/12 slices respectively.

Thiopental at a concentration-dependent manner shortened ripple episodes by reducing the number of ripples in each episode, without changing the ripple frequency (Fig. 4). Taking into account that thiopental prolonged single SPW it resulted that less of the SPW waveform was accompanied by a ripple episode following drug application. Thiopental significantly reduced the amplitude and the power of ripple oscillation. The ripple number and the duration of ripple episode were proven the most sensitive measures, with the drug significantly affecting these at the concentration onset of $25 \mu \mathrm{M}$ (paired t-test, $P<0.01$ ) and 

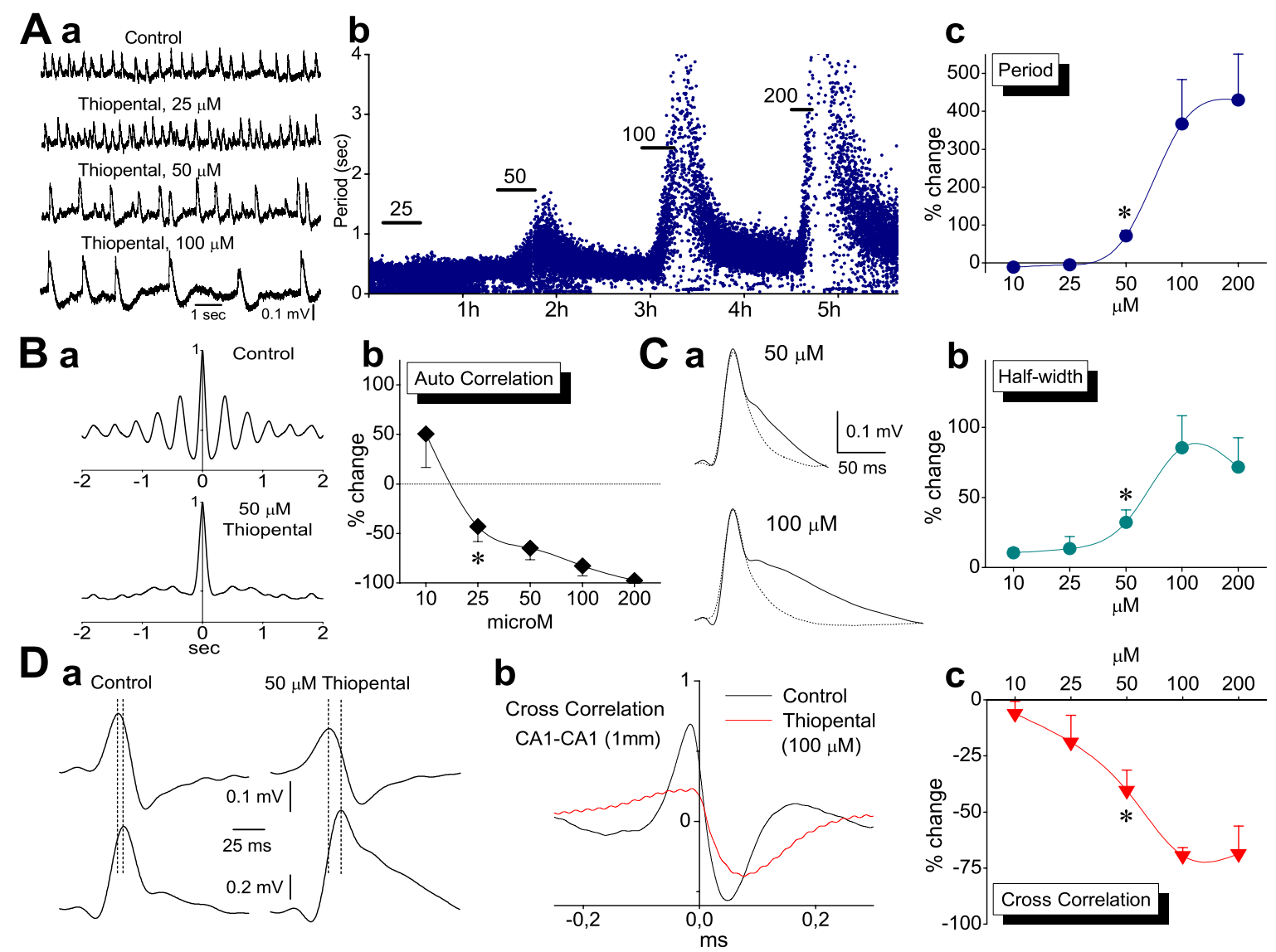

\section{Figure 3}

Effects of thiopental on Sharp Waves. A. Example of field recordings (a) and plot of instantaneous period (b) illustrating that thiopental induced a concentration-dependent and reversible increase in the inter-event period. Horizontal bars in "b" denote the time of application of consecutively larger drug concentrations. Relatively large data values of period during 100 and $200 \mu \mathrm{M}$ of the drug are curtailed for reasons of clarity of lower values. Note the great value dispersion of instant period during drug application at $\geq 50 \mu \mathrm{M}$. Data in "a" and "b" were obtained from two different slices. The collective data plot (percent changes) of period is shown in (c). The asterisk here, as in the subsequent collective plots in the figure, denotes the lowest concentration with statistically significant drug action (paired t-test, $P<0.00 \mathrm{I}$ at $50 \mu \mathrm{M}$ and $P<0.05$ at $100-200 \mu \mathrm{M}$ ). The number of slices studied at the five concentrations, of $10,25,50,100$ and $200 \mu \mathrm{M}$, were respectively $12,18,22$, 12 and 8 . Error bars not shown were smaller than the size of the symbol. B. Example of auto-correlation before and during $50 \mu \mathrm{M}$ thiopental (a) and collective auto-correlation plot (b) showing the disruption of rhythmicity at concentrations $\geq 25 \mu M$ (paired t-test, $P<$ 0.05 at $25 \mu \mathrm{M}$ and $P<0.0 \mathrm{I}$ at $\geq 50 \mu \mathrm{M}$ ). Numbers of slices studied at the five concentrations were 5, 6, I2, 8 and 4. C. Example of thiopental-induced prolongation of SPWs (a) at two different concentrations. Averages of low-pass filtered sweeps taken from a two minute epoch are shown. Dotted traces are control sweeps. The corresponding collective plot (b) shows that significant prolongation of single SPWs occurred at drug concentrations $\geq 50 \mu M$ (paired t-test, $P<0.0$ I). D. Effect of thiopental on SPWs' synchronization along the CAI region. Single SPWs simultaneously recorded from two locations along the CAI st. pyramidale, measuring I mm, are shown in "a", before (traces on the left) and during application of $50 \mu M$ thiopental (traces on the right). Sweeps were low-pass filtered in order to make feasible the time-discrimination of their peaks. Note the increased phase-lag (marked by dotted lines) during drug application $(9.25 \mathrm{~ms}$ ) compared with control condition ( $3.8 \mathrm{~ms})$. The cross-correlation plot from another slice (b) illustrates the large decrease of function value during drug application at $100 \mu \mathrm{M}$. The collective plot (c) shows that significant suppression of synchrony started at $25 \mu \mathrm{M}$ and reached a plateau at $100 \mu \mathrm{M}(P<0.05$ at $50 \mu \mathrm{M}$ and $P<0.0 \mathrm{I}$ at $\geq 50 \mu \mathrm{M})$. Numbers of slices studied at the five concentrations were 3, 5, 5, 4 and 4 . 
reaching maximal effect values at the concentration of 50 $\mu \mathrm{M}(P<0.001$; Fig. $4 \mathrm{C})$. The power of ripple oscillation was significantly reduced at concentrations $\geq 50 \mu \mathrm{M}(P \leq$ $0.01)$, whereas the amplitude was significantly affected at concentrations of 100 and $200 \mu \mathrm{M}(P<0.05$; Fig. 4C). Even at high concentrations thiopental only induced a small, statistically non significant reduction in the frequency of the oscillation (maximal reduction by $17 \pm 2.6$ $\%$ at $100 \mu \mathrm{M})$. It is interesting that at the lowest concentration used $(10 \mu \mathrm{M})$, the drug produced a consistent, yet statistically insignificant increase in the power of ripple oscillation (by $14.87 \pm 11.6 \%$; Fig. 4B-b,C), and a small acceleration of the rate of SPWs (reduction in period by $11.1 \pm 4.5 \%$; Fig. 3C), reminiscent of the EEG-activation at very light levels of general anesthesia [54].

It has been shown that thiopental reduces neuronal excitability [56]. In order to examine the action of the thiopental on the neuronal excitability, we measured SPW-Rassociated multiunit activity before and during application of the drug [57]. The calculation of rate was made using the same time window at control and drug conditions. The duration of the window equated to the time around the maximum rate value, which included the 75\% of the multiunit rate histogram. Thus, differences in the rate could be attributed to actual changes in the rate rather than to the total number of units fired during an SPW-R episode, taken into account that the drug induced shortening of SPW-R episodes. Thiopental produced significant and reversible reduction in the mean rate of multiunit activity by $43.8 \pm 6.5 \%(\mathrm{n}=9 ; P<0.05)$ (Fig. $4 \mathrm{D})$.

Previous studies have shown that thiopental reduces excitatory synaptic events but only at concentrations greater than $50 \mu \mathrm{M}$ [58-60]. We examined the effect of thiopental (50 and $100 \mu \mathrm{M}$ ) on the evoked field excitatory postsynaptic potential (fEPSP) recorded from the CA1 st. radiatum. Experiments were performed using the half-maximal fEPSP found on the base of input/output curve. In line with previous observations $[58,60]$ we found that thiopental did not affect fEPSPs at $50 \mu \mathrm{M}$ (Fig. 5). However, in contrast to previous studies $[58,59,61]$ we did not observe any significant effect of thiopental at $100 \mu \mathrm{M}$.

Generation of SPW-Rs does not require activation of NMDA receptors [31,45,62-64]. However, conditions facilitating NMDA receptor activation, such as low magnesium medium, or direct exogenous activation of NMDA receptors, may affect SPW-R activity [64]. On the other hand, thiopental $(50 \mu \mathrm{M})$ elicits burst suppression activity in the neocortex by a mechanism involving activation of NMDA receptors $[58,65]$. From a phenomenological point of view, there was a similarity between spontaneous activity observed in the present study under high drug concentrations and burst suppression activity (i.e. both are low-frequency high-voltage activity separated by periods of silence). Using recordings of SPW-R activity from the CA1 field, we examined whether NMDA receptors participate in the effects produced by thiopental at the concentrations of 50 or $100 \mu \mathrm{M}$. As shown in figure 6 , in the presence of NMDA receptor antagonist CPP $(10 \mu \mathrm{M})$, thiopental produced similar effects to those observed when the drug was administered alone, in standard medium. In particular, thiopental, at both concentrations (i.e. 50 and $100 \mu \mathrm{M}$ ) significantly increased the period of SPWs and prolonged single SPWs without affecting the amplitude of the waves and significantly reduced their rhythmicity $(P<$ $0.05 ; \mathrm{n}=9$ and $\mathrm{n}=8$ at 50 and $100 \mu \mathrm{M}$ respectively) (Fig. $6 \mathrm{~A}-\mathrm{C})$. Furthermore, the drug significantly reduced the quantity of ripples (i.e. their number, duration and power, $P<0.05 ; \mathrm{n}=7$ and $\mathrm{n}=5$ at 50 and $100 \mu \mathrm{M}$ respectively) without affecting the ripple frequency (Fig. 6D; examples shown in inserts of Fig. 6A \&6B). At $100 \mu \mathrm{M}$, thiopental abolished SPW-R activity in two out of ten slices.

\section{Phenobarbital effects on in vitro SPW-R complexes}

Phenobarbital was applied at the concentrations of 25 , $50,100,200$ and $400 \mu \mathrm{M}$ and its effects on SPW-R activity were studied with recordings made from the CA1 field. Clinically relevant serum concentrations of phenobarbital range from 40 to $160 \mu \mathrm{M}$ [66-68]. Free serum concentrations exceeding $100 \mu \mathrm{M}$ produce severe sedation [69]. Given that cerebrospinal fluid concentration of phenobarbital is about half of the free serum levels [70], the maximum values of therapeutic (anticonvulsant) cerebrospinal fluid concentrations does not usually exceed $100 \mu \mathrm{M}$. As shown in the figures 7 and 8, phenobarbital at the concentration of $25 \mu \mathrm{M}$ had no significant effect on SPW-R activity. At the concentrations of 50 and $100 \mu \mathrm{M}$ it significantly accelerated the rate of SPWs without affecting any of the other characteristics of SPWs or the ripple oscillation. At concentrations greater than 100 $\mu \mathrm{M}$ the drug significantly slowed down the rate of SPWs (Fig. 7A). Significant effects on other measures were observed only at the highest concentration used $(400 \mu \mathrm{M})$ which corresponded to the highest clinically employed concentrations $[42,66-69]$. Specifically, only at a concentration of $400 \mu \mathrm{M}$ did phenobarbital significantly reduce the auto-correlation of SPWs (Fig. 7B), significantly increase the half-width (Fig. 7C) and significantly reduce the quantity of ripples (number, duration and power, Fig. 8 ). At the very high concentration of $1.6 \mathrm{mM}$ abolishment of the spontaneous activity was observed $(n=3)$.

\section{Discussion}

The present findings demonstrate that thiopental, at clinically relevant concentrations known to impair memory, produces a significant reduction in the incidence, rhythmicity and synchrony of hippocampal SPWs and a concomitant reduction in the quantity, but not in the 

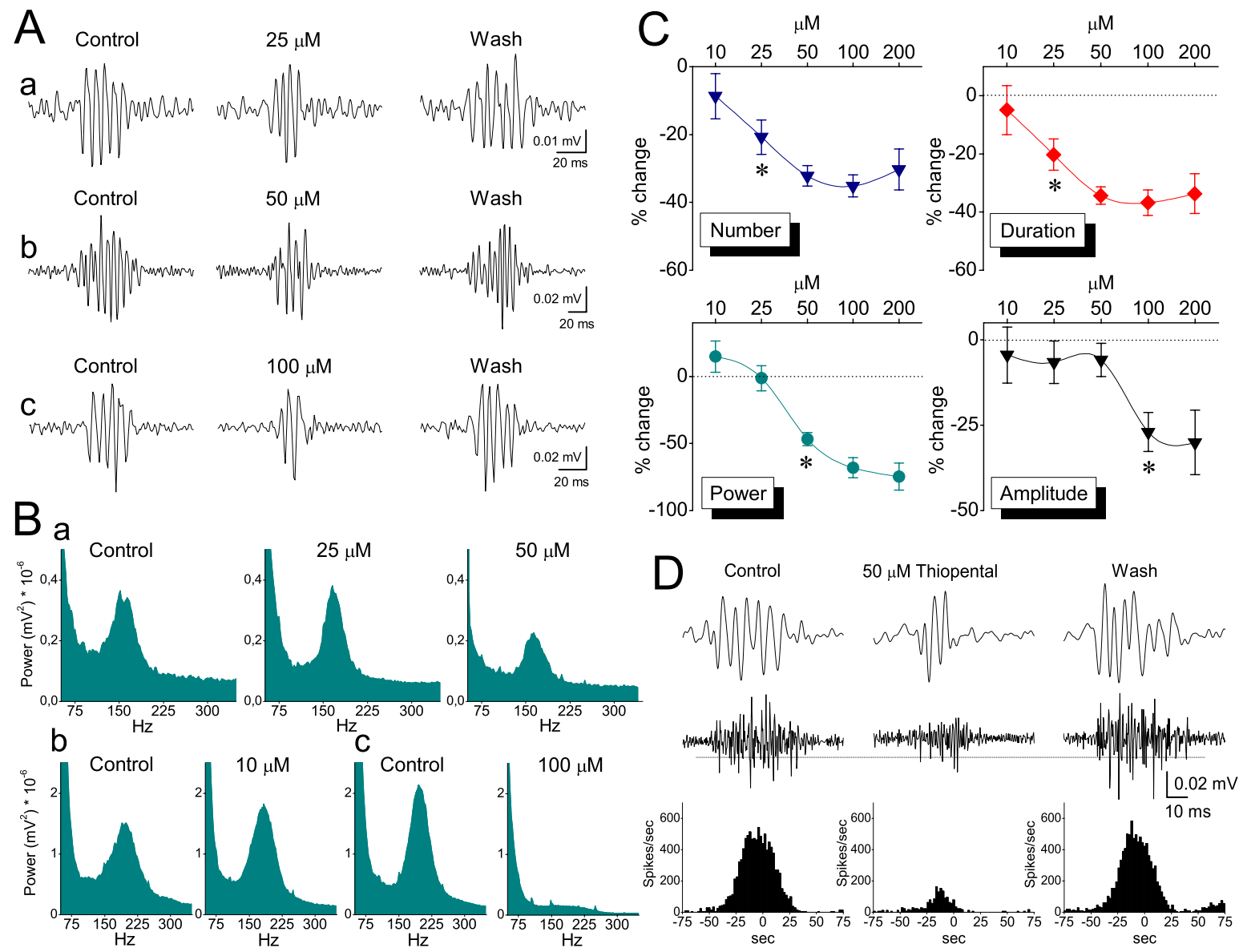

\section{Figure 4}

Effects of thiopental on Ripple oscillation. A. Examples of ripple oscillation (filtered traces) from three slices (a-c) illustrating the concentration-dependent reversible reduction in number of ripples and duration of ripple episode by thiopental. Note that even at $100 \mu \mathrm{M}$ of the drug, which strongly suppressed the amount of ripples, the oscillation frequency remained unchanged. B. Power spectra from three experiments (a-c) showing the reduction of ripple power at 50 and $100 \mu M$ but not at lower concentrations. C. Plots of collective data of drug effects (percent changes) on the various measures of ripple oscillation. Asterisks mark the lowest concentration with statistically significant drug action (see text for details of statistical analysis). Note that ripple number and ripple episode duration were more sensitive than ripple power and ripple amplitude. Measures of number, duration and amplitude for each of the five drug concentrations (I0, 25, 50, 100 and $200 \mu \mathrm{M})$ were respectively collected from 10, 12, 17, 10 and 8 slices. The corresponding numbers of slices for ripple power measures were respectively 12, 14, 22, 15, and 9. D. Recordings of ripples (upper traces) and multiunits (middle traces), revealed after filtering original records, showing the thiopental-induced reduction in the rate of multiunits during ripple episodes. Dotted line indicates the threshold level set in this experiment for spike detection. Histograms of multiunit rate (bottom panel) triggered by peaks of SPWs (not shown) used to measure the mean rate under the different experimental conditions. 


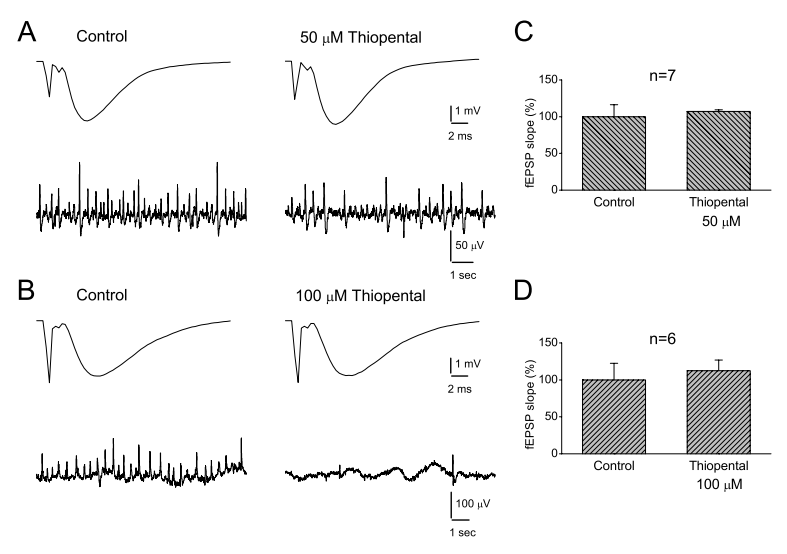

\section{Figure 5}

Thiopental did not affect fEPSPs. A-B. Evoked fEPSPs from CAI st. radiatum (upper traces, averages of ten sweeps) and continuous records of SPW-Rs from CAI st. pyramidale (lower traces) obtained in normal medium (left panels) and in medium containing 50 or $100 \mu \mathrm{M}$ of thiopental (right panels). fEPSPs and spontaneous activity were simultaneously recorded from two neighboring slices in "A" and from the same slice in "B". Note that the drug did not affect fEPSPs despite its suppressive effect on spontaneous activity. C-D. Grouped data of fEPSP slope for the two concentrations of thiopental. The drug did not significantly change the slope of fEPSP at any concentration.

frequency, of SPW-associated ripple oscillation. On the other hand, clinically relevant concentrations of phenobarbital did not significantly affect SPW-R complexes.

\section{Thiopental effects on in vitro SPW-R complexes}

Thiopental acts in slowing or disrupting gamma [71-73], beta [61] and theta oscillations [58,65]. The present study examined, for the first time, the effects of the drug on both SPWs and ripple oscillation. Previous in vivo studies have shown that the barbiturate pentobarbital slows down or abolishes SPWs at pre-anesthetic or anesthetic doses respectively $[12,74]$. The general anesthetic methohexital displays analogous effects on in vitro SPWs [75], and the inhaled anesthetic halothane prevents the appearance of ripples [48]. We observed that thiopental induced concentration-dependent slowing and disorganization of SPWRs, resulting apparently in abolishment of the spontaneous activity at high drug concentrations. Thiopental strongly reduced the rate of SPWs and significantly prolonged single SPWs at concentrations producing sedation $(\sim 50-150 \mu \mathrm{M})[53,54]$ and anesthesia $(>150 \mu \mathrm{M})[49,53-$ 55], but see also [50].

SPWs generation depends on excitatory and inhibitory synaptic transmission mediated by glutamatergic non-
NMDA $[28,29,31,62,76]$ and GABA $_{A}$ receptors $[28,29,62]$ respectively, and intense activation of inhibitory interneurons has been observed in vivo $[15,47,48,77]$ and in vitro [78]. SPW-associated ripple oscillation is a high-frequency $(100-200 \mathrm{~Hz})$ field event generated from the interaction between pyramidal cells and inhibitory interneurons $[8,16,46-48,79]$, with proposed prominent role of the interneurons [46-48].

At the cellular level, thiopental enhances $\mathrm{GABA}_{\mathrm{A}}$ receptormediated phasic inhibitory events [58-60,80-82], characteristically prolonging them [58-60,80,81]. The degree of drug-induced prolongation of inhibitory postsynaptic currents or potentials (IPSC/P) has been correlated to the degree of frequency reduction of those network oscillations, like theta [58], gamma and beta [60,61,71], whose period is at the range of IPSC duration. SPWs occurring every $\sim 0.5 \mathrm{sec}$, display a period longer than the duration of fast IPSPs, making thus less likely the involvement of enhanced $\mathrm{GABA}_{\mathrm{A}}$-mediated phasic inhibition in the druginduced reduction of the rate of SPWs. However, as suggested by recent data [83], the important implication of phasic GABAergic transmission in the initiation of SPW-R events should be taken into account and therefore its role on the rate of SPWs should not be ruled out. At concentrations $\geq 50 \mu \mathrm{M}$ thiopental enhances $\mathrm{GABA}_{\mathrm{A}}$ receptor-mediated tonic inhibition in hippocampal pyramidal cells [58,71] and interneurons [56], and directly activates $\mathrm{GABA}_{\mathrm{A}}$ receptors $[58,82]$. Enhancement of tonic inhibition affects neuronal excitability [56,84-86], and modeling data implicates tonic inhibition in slowing network oscillations [61,72]. Moreover, slowing of SPWs occurs under conditions of reduced neuronal excitability [87]. In the present study, thiopental reduced neuronal excitability, as observed by the reduction of unit activity. Therefore, the enhancement of tonic inhibition and the direct activation of $\mathrm{GABA}_{\mathrm{A}}$ receptors appears a likely explanation for the slowing down of SPWs. Thiopental could affect the rate of SPW-R activity by disturbing excitatory synaptic transmission, since slowing or even abolishment of SPWs has been observed whenever excitatory synaptic transmission is reduced [29], (Papatheodoropoulos, unpublished observations). However, we did not observe any significant drug effect on the fEPSPs.

Thiopental prolongs IPSPs in pyramidal neurons and in the present study the drug significantly prolonged SPWs. During in vitro SPWs both depolarizing and hyperpolarizing components are observed in principal neurons $[31,45,62,63]$, although in CA3 pyramidal cells some authors have observed only depolarizing potentials [75]. In our model the most prominent intracellular correlate of SPWs in CA1 pyramidal neurons is a $\mathrm{GABA}_{\mathrm{A}}$ receptormediated hyperpolarization [28]. Thus, the prolongation of SPWs induced by thiopental might involve to some 


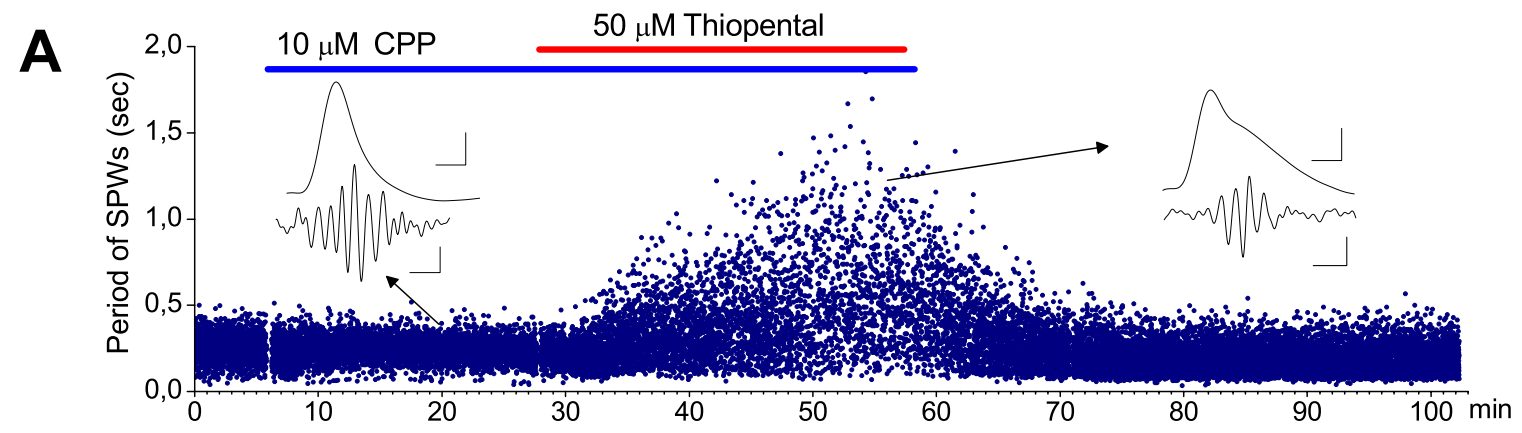

B
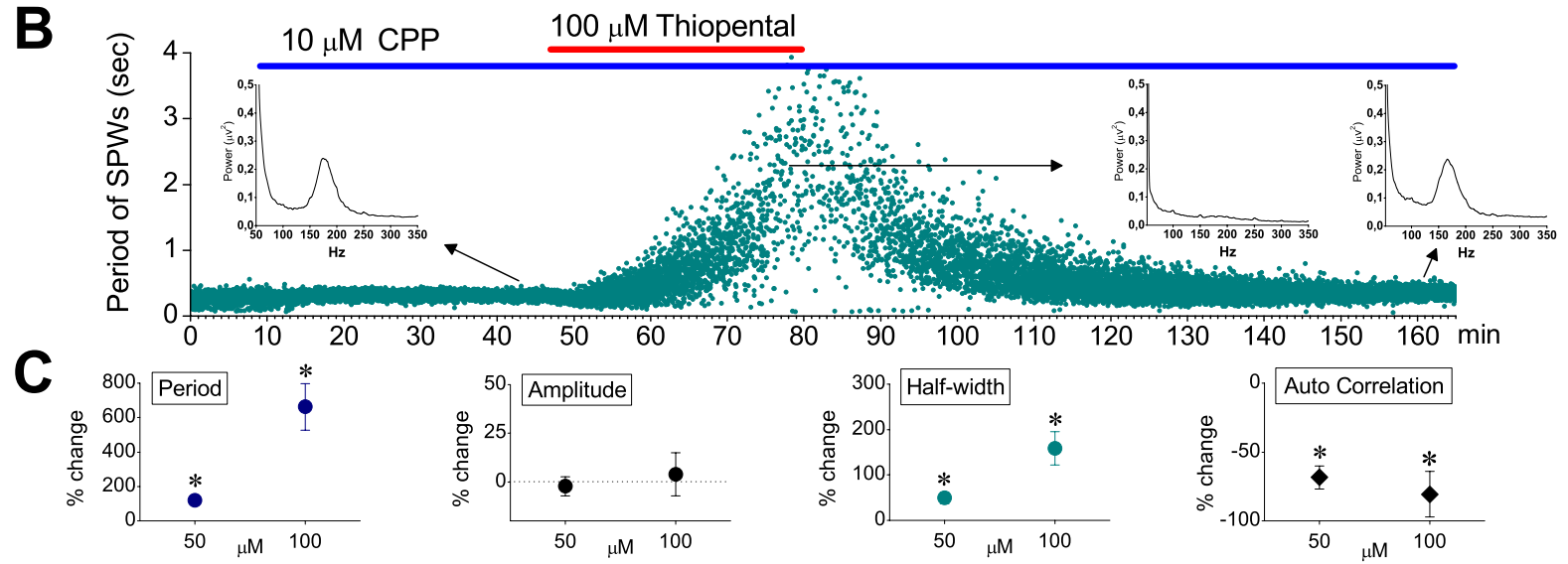

D
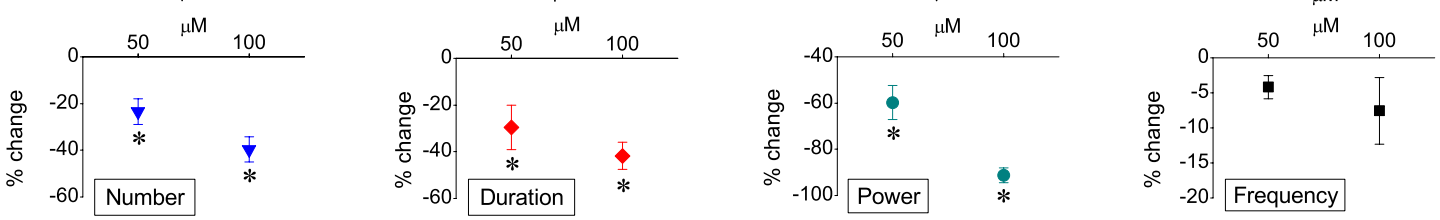

\section{Figure 6}

Thiopental action on SPW-Rs does not involve NMDA-mediated synaptic transmission. A. Representative histogram of instantaneous period of SPW-R activity recorded from the CAI st. pyramidale. Thiopental ( $50 \mu \mathrm{M}$, red bar), applied in the presence of NMDA receptor antagonist CPP $(10 \mu \mathrm{M}$, blue bar) produced reversible reduction in the rate of SPWs, a similar effect to that observed when the anesthetic was applied alone (compare with Fig. 3A). Inserts show examples of SPWs

(traces on the top, low-pass filtered) and ripples (traces on the bottom, band-pass filtered) selected from times before and during thiopental application (arrows indicating the panel on the left and right respectively). Note that under thiopental SPWs are prolonged and ripple episode was shortened, containing decreased number of ripple waves. Calibration bars in the inserts: 50 $\mu \mathrm{V}, 25 \mathrm{~ms}$ for SPW; $25 \mu \mathrm{V}, 50 \mathrm{~ms}$ for ripples. B. Histogram of instantaneous period of SPW-R activity recorded from the CAI st. pyramidale of a slice which received $100 \mu \mathrm{M}$ of thiopental (red bar) in the presence of CPP (blue bar). Inserts show the power spectra, at the ripple range, generated from epochs of 2 min taken from the different conditions (i.e. in CPP, in thiopental and after washing-out thiopental) as indicated by arrows. C-D. Collective data of the effects of thiopental on SPWs' (C) and Ripples' (D) measures in the presence of CPP. Measures of SPWs and Ripples were obtained from 9 and 7 slices respectively, at the concentration of $50 \mu \mathrm{M}$ and from 8 and 5 slices respectively at the concentration of $100 \mu \mathrm{M}$. Asterisks indicate statistically significant drug effects (paired t-test, at $P<0.05$ ). Error bars not shown were smaller than the size of the symbol. 

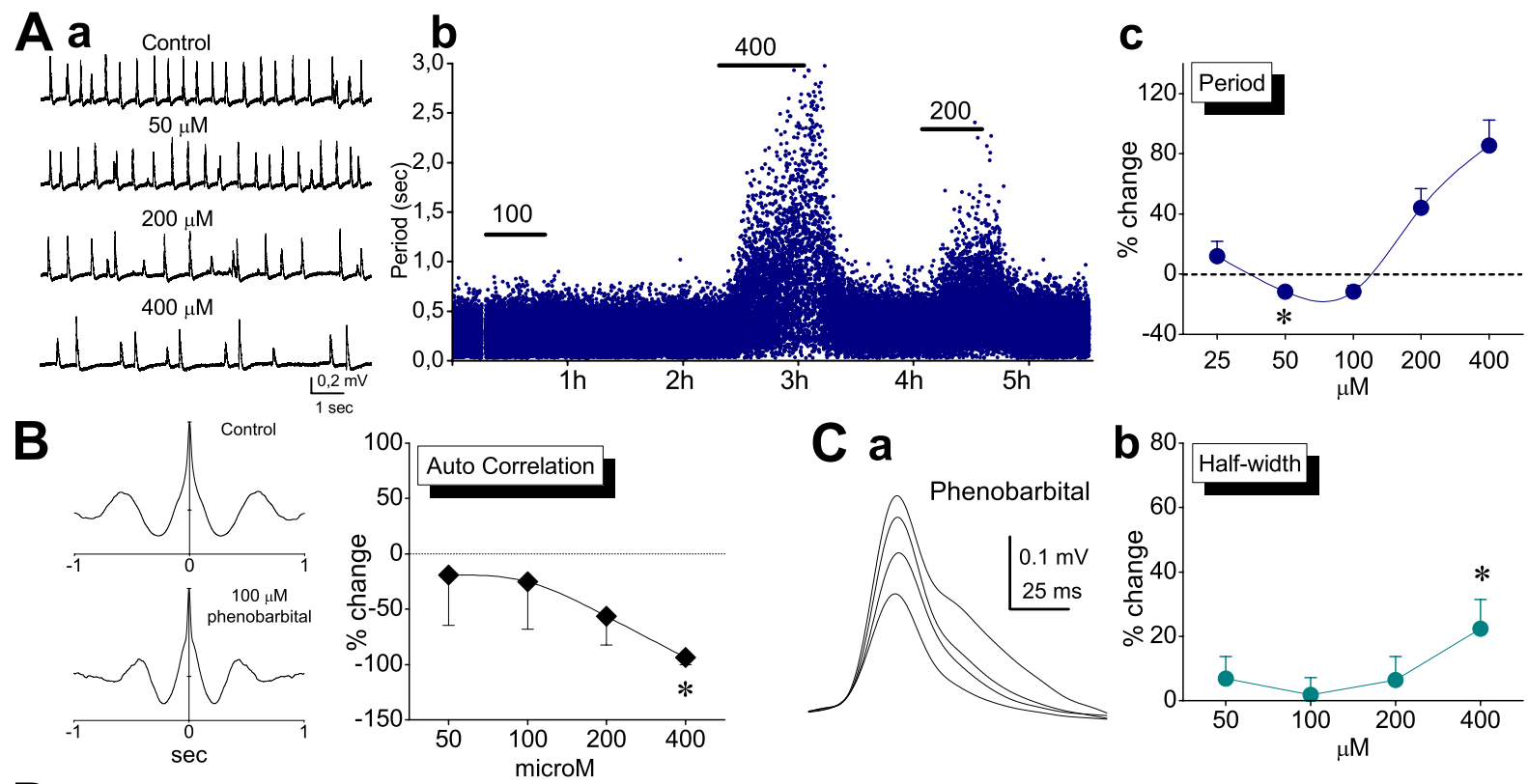

D
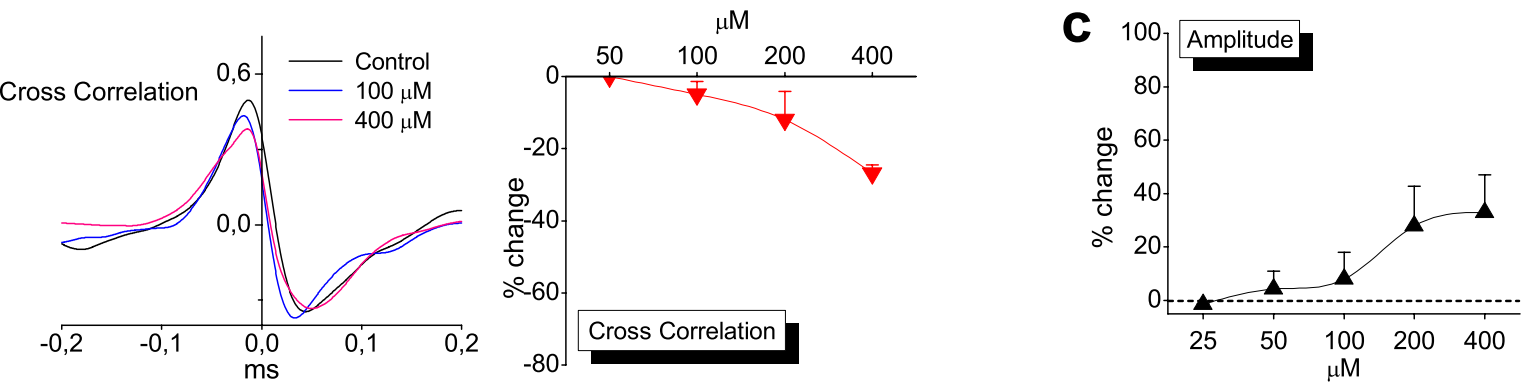

\section{Figure 7}

Effects of phenobarbital on SPWs. A. SPW-R complexes recorded from a slice bathed in normal medium and under consequently increasing concentrations of phenobarbital (a) showing that the rate of spontaneous activity was increased at 50 and $100 \mu \mathrm{M}$ and reduced at 200 and $400 \mu \mathrm{M}$ (asterisk denotes the lowest drug concentration with statistical significance effect, paired t-test, $P<0.00$ I paired $t \mathrm{t}$-test, $P<0.05)$. In the plot of instantaneous period $(\mathrm{b})$ note that even at the highest concentration $(400 \mu \mathrm{M})$ phenobarbital did not abolish spontaneous activity. Measures for constructing the plot of collective data (c) were obtained from 3, 6, 10, 12 and 18 slices respectively for the five drug concentrations. B. Example of auto-correlation analysis for SPWs recorded in one slice before and during application of $100 \mu \mathrm{M}$ of phenobarbital (diagram on the left). The collective data plot (diagram on the right) illustrates that only at $400 \mu \mathrm{M}$ did the drug significantly reduce rhythmicity of SPWs (asterisk, $P<0.05$ ). Data were obtained from 6, 10, 10 and 12 slices respectively for the four drug concentrations. C. Averages of filtered SPWs recorded from an epoch lasting two minutes (a) obtained from a slice bathed in normal medium (trace with the smallest amplitude) and increasing concentrations of phenobarbital $(50,200$ and $400 \mu \mathrm{M}$, traces with consecutively increasing amplitude). Note the concomitant increase in the falling phase and the amplitude of the potentials. The drug significantly increased half-width of SPWs at the highest concentration of $400 \mu \mathrm{M}$ (b). However, the drug did not significantly change the amplitude of SPWs at any concentration (c). Data in collective plots were obtained from 6, 10, 12 and 18 slices respectively for the four drug concentrations in half-width and from 3, 6, 10, 12 and 18 slices for the five concentrations in amplitude. D. Phenobarbital significantly decreased synchronization only at $400 \mu \mathrm{M}$, as illustrated in the example (on the left) and collective diagram (on the right, paired t-test, $P<0.05$ ). The concentration of $25 \mu \mathrm{M}$ is missing from the plots of auto-correlation, half-width and cross-correlation because measures of these variables were obtained from only one experiment. 

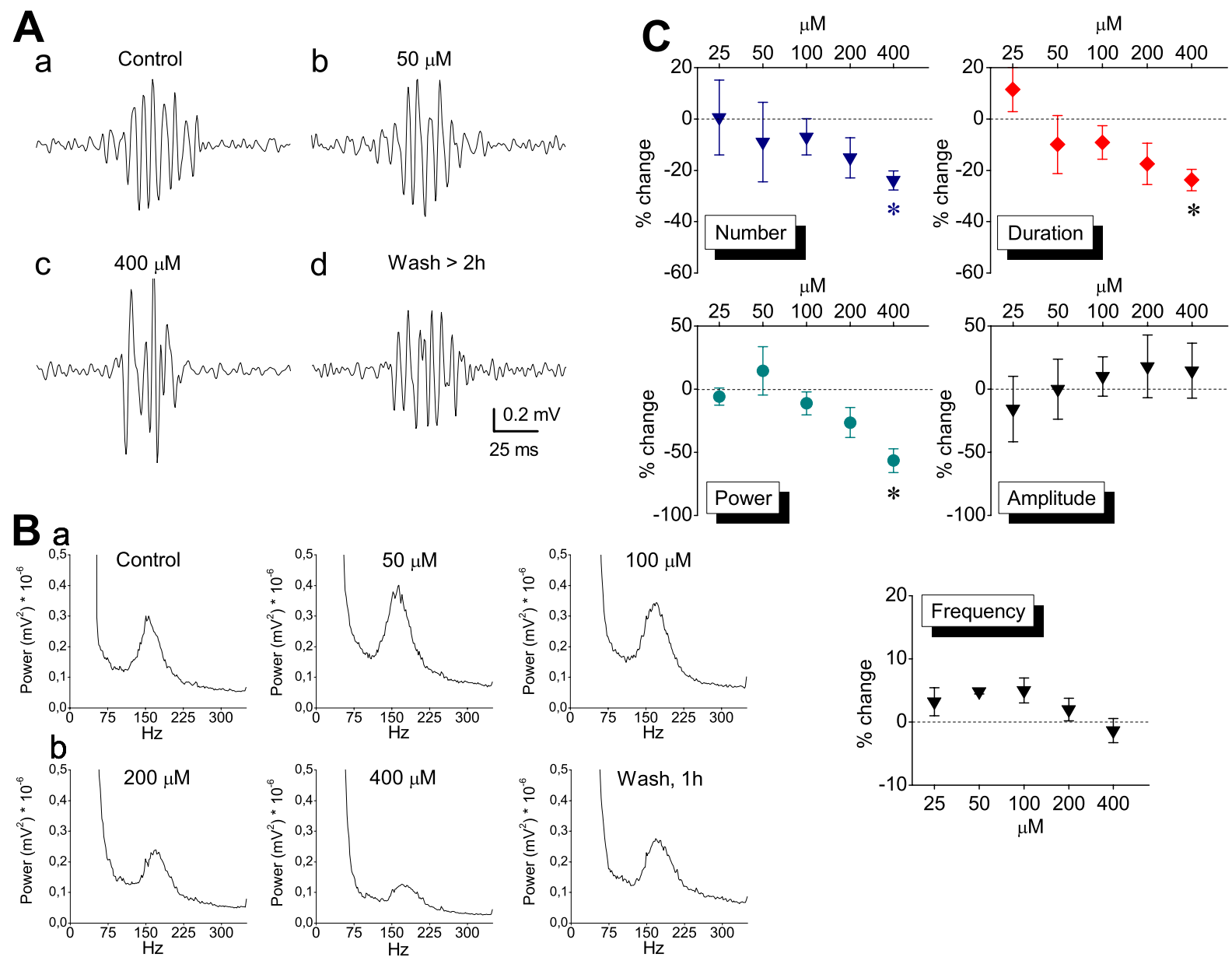

\section{Figure 8}

Effects of phenobarbital on Ripple oscillation. A. Examples of ripple oscillation obtained from one recording session showing that phenobarbital reversibly shortened ripple episode only at $400 \mu \mathrm{M}$ (asterisks, paired t-tests, $P<0.05$ ). B. Power spectra obtained from different times of a single experiment illustrating the reduction in ripple power only at high drug concentrations $(200$ and $400 \mu \mathrm{M})$. C. Diagrams of collective data for the different measures of the ripple oscillation. Note that the reducing effect of phenobarbital on number, duration and ripple power was statistically significant (asterisks, $P<0.05$ ) only at the highest concentration of $400 \mu \mathrm{M}$. Measures of the above variables (except power) at the five drug concentrations were obtained from 2, 3, 7, 5 and 9 slices. Values of power were obtained from 4, 7, 12, 9 and I 2 slices.

extends prolongation of $\mathrm{GABA}_{\mathrm{A}}$ receptor-mediated IPSPs in pyramidal cells. In this line, the absence of thiopental effect on the amplitude of SPWs is consistent with the observation that the drug, similarly to other barbiturates, does not affect the amplitude of $\mathrm{GABA}_{\mathrm{A}}$ receptor-mediated synaptic events [58-60,80], but see also [82].

In similarity to the previously observed disruptive effects of thiopental on rhythmicity and synchronization of in vitro theta, gamma and beta oscillations $[58,61,72]$, at clinically relevant concentrations $(\geq 25 \mu \mathrm{M})$, thiopental strongly suppressed rhythmicity and spatial synchronization of SPWs. The high degree of synchronization is actually one of the major common characteristics between in vivo $[12,88]$ and in vitro SPWs [27-30], whereas rhythmicity characterizes mostly the in vitro [31] (Fig. 1E) rather than the in vivo SPWs [12]. Disruption of synchrony of network oscillations along the CA1 region occurs as a result of the combination of the prolongation of $\mathrm{GABA}_{\mathrm{A}}$ receptor-mediated synaptic events with 
enhanced tonic inhibition [72]. Thus, the thiopentalinduced enhancement of $\mathrm{GABA}_{\mathrm{A}}$ receptor-mediated phasic and tonic conductances might also underlie the drug effects on synchrony and rhythmicity of SPWs.

Ripple oscillation was affected by thiopental at concentrations $\geq 25 \mu \mathrm{M}$. During ripple oscillation certain types of interneurons and a small fraction of pyramidal cells increase their activity following a temporally very precise firing pattern [46-48,77]. Therefore, excitability changes in these neurons would predict alterations in ripple oscillation characteristics. Among interneurons, bistratified and basket cells selectively fire during the whole ripple episode [77]. Thus, presumably the activity of these interneurons determines the duration of ripple episodes. We hypothesized that thiopental-induced reduction of excitability in bistratified and basket cells is critically involved in the drug effects on ripple oscillation. Interestingly, recent evidence [89] suggests that these particular types of interneurons (i.e. bistratified and basket cells) are at a relatively higher state of tonic inhibition compared to other types of inteneurons. Hippocampal interneurons but not pyramidal cells possess a baseline $\mathrm{GABA}_{\mathrm{A}}$ receptor-mediated tonic inhibition [85]. It might then be the case that interneurons, compared with pyramidal cells, display a greater susceptibility to thiopental-induced reduction in excitability through enhancement of tonic inhibition. This is consistent with the lower drug concentration needed to reduce ripple quantity (duration and number) compared with SPW's rate and duration. Furthermore, it supports the important role of interneurons in normal ripple generation, although oscillations at the ripple's frequency range can be observed under experimental conditions of disinhibition $[83,90,91]$.

\section{Comparison of effects between thiopental and phenobarbital}

The distinct effects of the two drugs on SPW-R activity, achieved at clinically relevant concentrations, resemble their differing sedative and amnesic effects. The effects of thiopental on SPW-Rs are presumably mediated via $\mathrm{GABA}_{\mathrm{A}}$ receptor mechanisms, since they are achieved at concentrations falling in the range of drug interaction with the $\mathrm{GABA}_{\mathrm{A}}$ receptor. On the other hand, the commonly employed anticonvulsant concentrations of phenobarbital $(<300 \mu \mathrm{M})$ [42,66-69] are lower than those for effective drug interaction with the $\mathrm{GABA}_{\mathrm{A}}$ receptor $(>300$ $\mu \mathrm{M})[42,68,92-95]$, but see also [96]. It appears therefore that the much lower effects of phenobarbital on SPW-R activity in comparison to those of thipoental's, might reflect its actual lower impact as an enhancer of $\mathrm{GABA}_{\mathrm{A}}$ receptor function.

\section{Implications}

SPW-R activity has been implicated in the processes of information transfer between hippocampus and neocortex subserving memory consolidation $[17,19,22,88,97]$. Thiopental-induced impairment of explicit memory occurs at drug serum concentrations less than $30 \mu \mathrm{M}$ $[1,35,98]$. Interestingly, the lowest concentration of the drug interfering with ripples and synchrony and rhythmicity of SPWs $(25 \mu \mathrm{M})$ actually equates to the Cp50 value for $50 \%$ explicit memory impairment [1]. Furthermore, the only concentration of phenobarbital $(200 \mu \mathrm{M})$ which significantly reduced the quantity of ripples was comparable to that producing explicit memory loss [42]. The present results show that thiopental affects the quantitative parameters of the ripple oscillation (i.e. the number, duration and power) but not the frequency of the oscillation. Consistently, it has been recently shown that cannabinoids, which induce memory impairment, produce reduction of the power but not of the frequency of the ripple oscillation [99]. Considering the proposed role of SPW-Rs in memory consolidation $[17,23,24]$, as well as the in vitro induction of SPW-Rs in association with long-term synaptic plasticity [31], the interfering effects of thiopental on SPW-R activity might disrupt the hippocampal network-dependent transformation of short-term into long-term memory storage. This is in line with previous data showing that the processes involved in the formation of long-term explicit memories are sensitive to anesthetic agents $[36,51,100]$.

SPW-R complexes can be triggered by neocortical input $[8,101,102]$. It could therefore be argued that thiopental exerts its amnesic actions by acting on the neocortical circuit, which only secondarily influences hippocampal function. On the other hand, the in vitro generation of SPW-Rs in hippocampal slices $[27,30,31,87]$, in the isolated whole hippocampus [29], as well as their in vivo occurrence in the grafted hippocampus $[29,43]$ show that they are an intrinsic hippocampal activity. Furthermore, the emergence of this activity is presumably based on strengthened synapses in the same local hippocampal circuit $[29,31,103]$. Consequently, the present evidence suggests that thiopental mediates its amnesic effects by directly acting on the local hippocampal circuit, and thus interfering with the hippocampo-neocortical communication, as observed also in the case of theta oscillation $[29,54]$. Finally, the present results are consistent with the emergent consensus on the weakening role that GABAergic transmission exerts on the memory processes [104].

\section{Conclusion}

Thiopental, presumably by disturbing the well regulated balance between excitation and inhibition, interferes with hippocampal SPW-R activity. The action of thiopental was observed at relatively low drug concentrations reported to 
induce mild sedation and explicit memory impairment. The drug-induced reduction in quantity but not frequency of the ripple oscillation is suggestive of the importance of the former parameter as a basic functional feature of the SPW-associated high-frequency oscillation. We hypothesize that the thiopental-induced effects on SPW-R activity are implicated in the drug-induced impairment of hippocampus-involving memory processes.

\section{Methods \\ Slice preparation}

Hippocampal slices were prepared from male Wistar rats, 4-10 weeks old, housed in a room with a controlled temperature $\left(22-24^{\circ} \mathrm{C}\right), 12 / 12$ hrs light-dark cycle. All measures were taken to minimize animal suffering and to reduce the number of the animals used, according to the European Communities Council Directive Guidelines (86/609/EEC) for the care and use of Laboratory animals. Animals were deeply anaesthetized with diethyl-ether and decapitated. The brain was removed and placed in chilled $\left(2-4^{\circ} \mathrm{C}\right)$ artificial cerebrospinal fluid (ACSF) and the two hippocampi were excised free. Using a McIlwain tissue chopper, transverse slices (500-550 $\mu \mathrm{m}$ thick) were prepared from the ventral hippocampus, as previously described [87]. The slices were immediately transferred on the two independent channels of an interface type recording chamber and maintained at a constant temperature of $32 \pm 0.2^{\circ} \mathrm{C}$. In some experiments the temperature was changed in order to observe its effects on the spontaneous activity (see Results). The slices were continuously humidified with $95 \% \mathrm{O}_{2}$ and $5 \% \mathrm{CO}_{2}$ mixed gas and perfused at a rate of $0.8-1.0 \mathrm{ml} / \mathrm{min}$ with standard ACSF containing (in $\mathrm{mM}$ ): $124 \mathrm{NaCl} ; 4 \mathrm{KCl} ; 2 \mathrm{MgSO}_{4} ; 2 \mathrm{CaCl}_{2} ; 1.25$ $\mathrm{NaH}_{2} \mathrm{PO}_{4} ; 26 \mathrm{NaHCO}_{3} ; 10$ glucose; at pH 7.4, equilibrated with $95 \% \mathrm{O}_{2}$ and $5 \% \mathrm{CO}_{2}$ gas mixture. Drugs included thiopental (Pentothal, Abbott Laboratoires, S.p.A. Italy) phenobarbital (Sigma, USA) and the NMDA receptor antagonist 3-((R)-2-Carboxypiperazin-4-yl)-propyl-1-phosphonic acid (CPP, Tocris, UK). All drugs were prepared as stock solutions and then were dissolved in ACSF and bath applied. CPP was applied for at least fifteen minutes before the application of thiopental. Thiopental and phenobarbital were applied for thirty minutes. In some experiments thiopental was applied for longer periods, as indicated in figures.

\section{Electrophysiological Recordings}

Field potentials were recorded from CA1 or CA3 stratum pyramidale or st. radiatum using carbon fibre electrodes, of a diameter either $7 \mu \mathrm{m}$ (homemade) or $10 \mu \mathrm{m}$ (World Precision Instruments Inc., USA). A bipolar platinum/ iridium electrode $(25 \mu \mathrm{m})$ located in stratum radiatum was used for electrical stimulation of the Schaffer collaterals (pulses: 0.3-0.9 mA/0.1 ms). Spontaneous field potentials were gradually organized in the ventral hippoc- ampal slices during the first 2-3 h of their maintenance in the recording chamber, under standard conditions. Spontaneous activity was fully organized in terms of amplitude and frequency after about three hours from slice placement on the chamber (Fig. 1A). Stabilized activity was recorded constantly for at least three hours thereafter without interruption or considerable decline in amplitude and frequency of occurrence. Activity in many slices was stable for more than seven hours. The consistency over time (i.e. the stability of phenomenological characteristics, like frequency and amplitude) allows the detailed examination of pharmacological effects over a wide time scale. In order to determine the degree of synchrony of sharp waves (SPWs) across CA1 st. pyramidale two simultaneous field recordings were made along the pyramidal layer at a fixed distance of $1 \mathrm{~mm}$.

\section{Data processing, Measurements and Analysis}

Signals were band-pass filtered at $0.5 \mathrm{~Hz}-2 \mathrm{kHz}$ using a Neurolog amplifier system (Digitimer Limited, UK), and a Grass AC/DC amplifier when double simultaneous recordings were performed. Data were digitized at $4 \mathrm{kHz}$ and stored in a computer disk using the CED 1401-plus interface and analyzed off-line using the Spike2 and Signal software (Cambridge Electronic Design, Cambridge, UK).

Spontaneous activity in stratum pyramidale consisted of a positive slow wave consistently ridden by a burst-like high-frequency activity. The latter was mainly manifested during slow wave's rising and peaking phase (Fig. 1C1). Measures of the spontaneous activity were performed on the slow and high frequency components, which were disclosed after filtering original recordings at different frequency windows (Fig. 1C-2,C3 and 1C4). Specifically, SPWs were detected after low-pass filtering the original signal at $35 \mathrm{~Hz}$ and setting a threshold at a level in which all putative events, verified by visual inspection, were marked. In some experiments, in which the amplitude of SPWs was greatly reduced during the pharmacological procedure, adjustment of the threshold was required in order to make the detection of all events in the record reliable. SPWs were quantified by the following measures: a) period, determined as the time interval between the peaks of successive waves; b) amplitude, determined as the voltage difference between the positive peak and the baseline; c) duration, determined as the time elapsed between the two points of intersection of the field positive waveform with the baseline; d) half-maximal width, determined as the time elapsed between the two points of intersection of the field waveform with the horizontal line passing through the half-maximal amplitude of the wave. Measures of duration and half-maximal width were performed on the average sweep calculated from at least thirty single events; e) auto-correlation, used as an index of the rhyth- 
micity of SPWs, was estimated by the amplitude of the first side-peak of the auto-correlogram [105]; f) cross-correlation, measured by the peak amplitude of the corresponding cross-correlogram calculated using simultaneous recordings from two slice locations with a distance between them of $1 \mathrm{~mm}$. Cross-correlation was used as an index of the synchronization of SPWs along the pyramidal layer. The measures of period, amplitude and duration of SPW were made from two minute long epochs of low-pass filtered record. Auto-correlation and crosscorrelation were obtained from a recording epoch lasting ten to twenty seconds. Ripples were detected after bandpass filtering original records at $80-300 \mathrm{~Hz}$ (1C-3) and setting a threshold at four times the standard deviation of event-free baseline noise. Furthermore, events were categorized as ripples only when episodes of at least three consecutive negative deflections were observed with delays between them of at least $2 \mathrm{~ms}$ and no more than $11 \mathrm{~ms}$, i.e. they should have a frequency falling within the range of $90-500 \mathrm{~Hz}$ [62]. Threshold was further verified by visual inspection. Ripples were therefore quantified by their: a) number of ripples inside a ripple event, estimated by the number of negative deflections inside an event; b) duration of the ripple event; $\mathrm{c}$ ) intra-ripple frequency, determined as the reciprocal of the value of the mean inter-ripple interval; d) amplitude, determined as the voltage difference between the positive and negative maximum in each ripple event. Measures of ripple characteristics from each slice or condition were made from thirty consecutive ripple events. Ripple power and frequency were additionally verified from power spectra applied to five minute long raw record. Multiunit activity was revealed by band-pass filtering data at $500-1000 \mathrm{~Hz}$, and the negative spikes were detected setting the threshold level four times the standard deviation of event-free baseline noise.

Examination of drug effects on SPW-R activity was performed only on those slices displaying stable activity for at least fifteen minutes. For that, the power of ripples and the auto-correlation in SPWs were on-line analyzed and monitored in a continuous manner. Whenever recordings were made from two locations in the same slice, cross-correlation analysis was also continuously monitored.

Values through the text are expressed as mean \pm S.E.M., and " $\mathrm{n}$ " indicates the number of slices included in the analysis. For statistical comparisons of the effects of thiopental and phenobarbital on SPW-Rs, measures were taken before drug application and thirty minutes after drug application. We used SPSS 14 for statistical analysis (paired and independent t-tests), Origin 7 to make figures and Reference Manager 10 to construct the list of references.

\section{Authors' contributions}

$\mathrm{CP}$ conceived of the study, made the experimental design, carried out most of the experiments, participated in the data analysis and wrote and prepared the manuscript. ES participated in some experiments and contributed to the data analysis. DK contributed to the data analysis. PD participated in the experimental work, contributed to the data analysis of most of the experiments and helped with the data archiving. All authors read and approved the final manuscript.

\section{Acknowledgements}

This work was supported by the European Social Fund (ESF), Operational Program for Educational and Vocational Training II (EPEAEK II), and particularly the Program PYTHAGORAS II.

\section{References}

I. Veselis RA, Reinsel RA, Feshchenko VA, Wronski M: The comparative amnestic effects of midazolam, propofol, thiopental, and fentanyl at equisedative concentrations. Anesthesiology 1997, 87:749-764.

2. Lubke GH, Kerssens C, Phaf H, Sebel PS: Dependence of explicit and implicit memory on hypnotic state in trauma patients. Anesthesiology 1999, 90:670-680.

3. Kerssens C, Lubke GH, Klein J, van der WA, Bonke B: Memory function during propofol and alfentanil anesthesia: predictive value of individual differences. Anesthesiology 2002, 97:382-389.

4. Ghoneim MM: Drugs and human memory (part 2). Clinical, theoretical, and methodologic issues. Anesthesiology 2004, 100: 1277-1297.

5. Eichenbaum $\mathrm{H}$ : Hippocampus: cognitive processes and neural representations that underlie declarative memory. Neuron 2004, 44: 109-120.

6. Roberts WA: Animal memory: episodic-like memory in rats. Curr Biol 2006, I 6:R60I-R603.

7. Shapiro ML, Kennedy PJ, Ferbinteanu J: Representing episodes in the mammalian brain. Curr Opin Neurobiol 2006, 16:70I-709.

8. Buzsaki G: Rhythms of the brain Oxford, Oxford University Press; 2006.

9. Pavlides C, Winson J: Influences of hippocampal place cell firing in the awake state on the activity of these cells during subsequent sleep episodes. J Neurosci 1989, 9:2907-2918.

10. Wilson MA, McNaughton BL: Reactivation of hippocampal ensemble memories during sleep. Science 1994, 265:676-679.

II. Lee AK, Wilson MA: Memory of sequential experience in the hippocampus during slow wave sleep. Neuron 2002, 19:1 I83-1194.

12. Buzsaki G: Hippocampal sharp waves: their origin and significance. Brain Res 1986, 398:242-252.

13. O'Keefe J, Nadel L: The hippocampus as a cognitive map. Oxford, Clarendon Press; 1978.

14. Suzuki SS, Smith GK: Spontaneous EEG spikes in the normal hippocampus. I. Behavioral correlates, laminar profiles and bilateral synchrony. Electroencephalogr Clin Neurophysiol 1987, 67:348-359.

15. Buzsaki G, Horvath Z, Urioste R, Hetke J, Wise K: High-frequency network oscillation in the hippocampus. Science 1992, 256: 1025-1027.

16. Draguhn A, Traub RD, Bibbig A, Schmitz D: Ripple (approximately $200-\mathrm{Hz}$ ) oscillations in temporal structures. J Clin Neurophysiol 2000, 17:361-376.

17. Siapas AG, Wilson MA: Coordinated interactions between hippocampal ripples and cortical spindles during slow-wave sleep. Neuron 1998, 21: I I23-1 I 28.

18. Buzsaki G, Leung LW, Vanderwolf $\mathrm{CH}$ : Cellular bases of hippocampal EEG in the behaving rat. Brain Res 1983, 287:139-171.

19. Foster DJ, Wilson MA: Reverse replay of behavioural sequences in hippocampal place cells during the awake state. Nature 2006, 440:680-683. 
20. Chrobak J], Buzsaki G: Selective activation of deep layer (V-VI) retrohippocampal cortical neurons during hippocampa sharp waves in the behaving rat. J Neurosci 1994, 14:6160-6170.

21. Sirota A, Csicsvari J, Buhl D, Buzsaki G: Communication between neocortex and hippocampus during sleep in rodents. Proc Natl Acad Sci U S A 2003, 1 00:2065-2069.

22. Buzsaki G: The hippocampo-neocortical dialogue. Cereb Cortex 1996, 6:81-92

23. Born J, Rasch B, Gais S: Sleep to remember. Neuroscientist 2006, 1 2:410-424

24. Buzsaki G: Memory consolidation during sleep: a neurophysiological perspective. I Sleep Res 1998, 7:17-23.

25. Antkowiak $B$ : In vitro networks: cortical mechanisms of anaesthetic action. Br J Anaesth 2002, 89:102-III.

26. Whittington MA, Faulkner HJ, Doheny HC, Traub RD: Neuronal fast oscillations as a target site for psychoactive drugs. Pharmacol Ther 2000, 86: I7I-190.

27. Maier N, Guldenagel M, Sohl G, Siegmund H, Willecke K, Draguhn A: Reduction of high-frequency network oscillations (ripples) and pathological network discharges in hippocampal slices from connexin 36-deficient mice. J Physiol 2002, 54I:52I-528.

28. Papatheodoropoulos C, Kostopoulos G: Spontaneous GABA(A)dependent synchronous periodic activity in adult rat ventral hippocampal slices. Neurosci Lett 2002, 3 I 9:17-20.

29. Wu C, Shen H, Luk WP, Zhang L: A fundamental oscillatory state of isolated rodent hippocampus. I Physiol 2002 540:509-527.

30. Kubota D, Colgin LL, Casale M, Brucher FA, Lynch G: Endogenous waves in hippocampal slices. J Neurophysiol 2003, 89:81-89.

31. Behrens CJ, van den Boom LP, de Hoz L, Friedman A, Heinemann U: Induction of sharp wave-ripple complexes in vitro and reorganization of hippocampal networks. Nat Neurosci 2005 , 8:1560-1567.

32. Osborn AG, Bunker JP, Cooper LM, Frank GS, Hilgard ER: Effects of thiopental sedation on learning and memory. Science 1967 I 57:574-576.

33. Reitan JA, Porter W, Braunstein M: Comparison of psychomotor skills and amnesia after induction of anesthesia with midazolam or thiopental. Anesth Analg 1986, 65:933-937.

34. Parker CJ, Oates JD, Boyd AH, Thomas SD: Memory for auditory material presented during anaesthesia. Br J Anaesth 1994, 72:181-184

35. Pryor KO, Veselis RA, Reinsel RA, Feshchenko VA: Enhanced visual memory effect for negative versus positive emotional content is potentiated at sub-anaesthetic concentrations of thiopental. BrJ Anaesth 2004, 93:348-355.

36. Grasshoff C, Drexler B, Rudolph U, Antkowiak B: Anaesthetic drugs: linking molecular actions to clinical effects. Curr Pharm Des 2006, I 2:3665-3679.

37. MacLeod CM, Dekabian AS, Hunt E: Memory impairment in epileptic patients: selective effects of phenobarbital concentration. Science 1978, 202: I 102-I I04.

38. Brown-Croyts LM, Caton PW, Radecki DT, McPherson SL: Phenobarbital pre-treatment prevents kainic acid-induced impairments in acquisition learning. Life Sci 2000, 67:643-650.

39. White KG, Harper DN, Watson JE: Effects of chronic phenobarbital administration on forgetting functions in pigeons. Pharmacol Biochem Behav 1994, 49:427-431.

40. Meador KJ, Loring DW, Moore EE, Thompson WO, Nichols ME Oberzan RE, Durkin MW, Gallagher BB, King DW: Comparative cognitive effects of phenobarbital, phenytoin, and valproate in healthy adults. Neurology 1995, 45:1494-1499.

41. Shannon HE, Love PL: Effects of antiepileptic drugs on working memory as assessed by spatial alternation performance in rats. Epilepsy Behav 2004, 5:857-865.

42. Jokeit $H$, Kramer G, Ebner A: Do antiepileptic drugs accelerate forgetting? Epilepsy Behav 2005, 6:430-432.

43. Buzsaki G, Czopf J, Kondakor I, Bjorklund A, Gage FH: Cellular activity of intracerebrally transplanted fetal hippocampus during behavior. Neuroscience 1987, 22:87|-883.

44. Harkness JE WJE: The Biology and Medicine of Rabbits and Rodents 3rd edition. Lea and Febiger; 1989.

45. Wu C, Luk WP, Gillis J, Skinner F, Zhang L: Size does matter: generation of intrinsic network rhythms in thick mouse hippocampal slices. I Neurophysiol 2005, 93:2302-2317.
46. Csicsvari J, Hirase H, Czurko A, Mamiya A, Buzsaki G: Oscillatory coupling of hippocampal pyramidal cells and interneurons in the behaving Rat. J Neurosci 1999, 19:274-287.

47. Klausberger T, Magill PJ, Marton LF, Roberts JD, Cobden PM, Buzsak G, Somogyi P: Brain-state- and cell-type-specific firing of hippocampal interneurons in vivo. Nature 2003, 42 I :844-848.

48. Ylinen A, Bragin A, Nadasdy Z, Jando G, Szabo I, Sik A, Buzsaki G: Sharp wave-associated high-frequency oscillation $(200 \mathrm{~Hz})$ in the intact hippocampus: network and intracellular mechanisms. J Neurosci 1995, I 5:30-46.

49. Becker KE Jr.: Plasma levels of thiopental necessary for anesthesia. Anesthesiology 1978, 49:192-196.

50. Franks NP, Lieb WR: Molecular and cellular mechanisms of general anaesthesia. Nature 1994, 367:607-6I4.

5I. Veselis RA, Feshchenko VA, Reinsel RA, Dnistrian AM, Beattie B Akhurst T]: Thiopental and propofol affect different regions of the brain at similar pharmacologic effects. Anesth Analg 2004, 99:399-408

52. Hung OR, Varvel JR, Shafer SL, Stanski DR: Thiopental pharmacodynamics. II. Quantitation of clinical and electroencephalographic depth of anesthesia. Anesthesiology 1992, 77:237-244

53. Gustafsson LL, Ebling WF, Osaki E, Stanski DR: Quantitation of depth of thiopental anesthesia in the rat. Anesthesiology 1996, 84:4I5-427.

54. Maclver MB, Mandema JW, Stanski DR, Bland BH: Thiopental uncouples hippocampal and cortical synchronized electroencephalographic activity. Anesthesiology 1996, 84: | 4 I I- | 424.

55. Librizzi L, Pastori C, de Grazia U, Croci D, de Curtis M: Rapid in vitro elimination of anesthetic doses of thiopental in the isolated guinea pig brain. Neurosci Lett 2005, 380:66-69.

56. Bieda MC, Maclver MB: Major role for tonic GABAA conductances in anesthetic suppression of intrinsic neuronal excitability. J Neurophysiol 2004, 92: I658-I667.

57. Antkowiak B: Different actions of general anesthetics on the firing patterns of neocortical neurons mediated by the GABA(A) receptor. Anesthesiology 1999, $91: 500-51$ I.

58. Lukatch HS, Maclver MB: Synaptic mechanisms of thiopentalinduced alterations in synchronized cortical activity. Anesthesiology 1996, 84: |425-|434.

59. Pittson S, Himmel AM, Maclver MB: Multiple synaptic and membrane sites of anesthetic action in the CAI region of rat hippocampal slices. BMC Neurosci 2004, 5:52.

60. Dickinson R, de Sousa SL, Lieb WR, Franks NP: Selective synaptic actions of thiopental and its enantiomers. Anesthesiology 2002 , 96:884-892.

6I. Faulkner HJ, Traub RD, Whittington MA: Anaesthetic/amnesic agents disrupt beta frequency oscillations associated with potentiation of excitatory synaptic potentials in the rat hippocampal slice. Br J Pharmacol 1999, I28:1813-1825.

62. Maier N, Nimmrich V, Draguhn A: Cellular and network mechanisms underlying spontaneous sharp wave-ripple complexes in mouse hippocampal slices. J Physiol 2003, 550:873-887.

63. Colgin LL, Jia Y, Sabatier JM, Lynch G: Blockade of NMDA receptors enhances spontaneous sharp waves in rat hippocampal slices. Neurosci Lett 2005, 385:46-5I.

64. Papatheodoropoulos C, Moschovos C, Kostopoulos G: Greater contribution of $\mathbf{N}$-methyl-D-aspartic acid receptors in ventral compared to dorsal hippocampal slices in the expression and long-term maintenance of epileptiform activity. Neuroscience 2005, I35:765-779.

65. Lukatch HS, Kiddoo CE, Maciver MB: Anesthetic-induced burst suppression EEG activity requires glutamate-mediated excitatory synaptic transmission. Cereb Cortex 2005, I 5: I322-I33I.

66. Schulz DW, Macdonald RL: Barbiturate enhancement of GABAmediated inhibition and activation of chloride ion conductance: correlation with anticonvulsant and anesthetic actions. Brain Res 1981, 209:177-188.

67. Crowder JM, Bradford HF: Common anticonvulsants inhibit $\mathrm{Ca2+}$ uptake and amino acid neurotransmitter release in vitro. Epilepsia 1987, 28:378-382.

68. Bourgeois BF: Pharmacokinetic properties of current antiepileptic drugs: what improvements are needed? Neurology 2000 , 55:SII-SI6.

69. Prichard JWR B.R.: Phenobarbital: mechanisms of action. In Anti epileptic drugs 4th edition. Edited by: Levy RH and Mattson RHMBS. New York, Raven Press; 1995:359-369. 
70. Painter MJ, Gaus LM: Phenobarbital. In The Treatment of Epilepsy: Principles and Practices Edited by: Wyllie E. Philadelphia, Lea and Febinger; 1993.

7I. Whittington MA, Jefferys JG, Traub RD: Effects of intravenous anaesthetic agents on fast inhibitory oscillations in the rat hippocampus in vitro. Br J Pharmacol 1996, I I 8: | 977-1986.

72. Faulkner HJ, Traub RD, Whittington MA: Disruption of synchronous gamma oscillations in the rat hippocampal slice: a common mechanism of anaesthetic drug action. $\mathrm{Br} J$ Pharmacol 1 998, I 25:483-492.

73. Dickinson R, Awaiz S, Whittington MA, Lieb WR, Franks NP: The effects of general anaesthetics on carbachol-evoked gamma oscillations in the rat hippocampus in vitro. Neuropharmacology 2003, 44:864-872.

74. Suzuki SS, Smith GK: Spontaneous EEG spikes in the normal hippocampus. V. Effects of ether, urethane, pentobarbital, atropine, diazepam and bicuculline. Electroencephalogr Clin Neurophysiol 1988, 70:84-95.

75. Wu C, Asl MN, Gillis J, Skinner FK, Zhang L: An in vitro model of hippocampal sharp waves: regional initiation and intracellular correlates. J Neurophysiol 2005, 94:741-753.

76. Colgin LL, Kubota D, Jia Y, Rex CS, Lynch G: Long-term potentiation is impaired in rat hippocampal slices that produce spontaneous sharp waves. J Physiol 2004, 558:953-96I

77. Klausberger T, Marton LF, Baude A, Roberts JD, Magill PJ, Somogyi P: Spike timing of dendrite-targeting bistratified cells during hippocampal network oscillations in vivo. Nat Neurosci 2004, 7:4I-47.

78. Wong T, Zhang XL, Asl MN, Wu CP, Carlen PL, Zhang L: Postnatal development of intrinsic GABAergic rhythms in mouse hippocampus. Neuroscience 2005, 134:107-120.

79. Chrobak JJ, Buzsaki G: Gamma and ripple oscillations: functional indices of hippocampal-enthorhinal interactions. In The parahippocampal region. Edited by: Witter $\mathrm{M}$ and Wouterlood $\mathrm{F}$. Oxford, Oxford University Press; 2002:127-138.

80. Hollrigel GS, Toth K, Soltesz I: Neuroprotection by propofol in acute mechanical injury: role of GABAergic inhibition. J Neurophysiol 1996, 76:2412-2422.

81. Cordato DJ, Chebib M, Mather LE, Herkes GK, Johnston GA: Stereoselective interaction of thiopentone enantiomers with the GABA(A) receptor. $\mathrm{Br} J$ Pharmacol 1999, I 28:77-82.

82. Yang CX, Xu H, Zhou KQ, Wang MY, Xu TL: Modulation of gamma-aminobutyric acid $A$ receptor function by thiopental in the rat spinal dorsal horn neurons. Anesth Analg 2006, 102: I | 14- I120.

83. Nimmrich V, Maier N, Schmitz D, Draguhn A: Induced sharp waveripple complexes in the absence of synaptic inhibition in mouse hippocampal slices. J Physiol 2005, 563:663-670.

84. Stell BM, Brickley SG, Tang CY, Farrant M, Mody I: Neuroactive steroids reduce neuronal excitability by selectively enhancing tonic inhibition mediated by delta subunit-containing GABAA receptors. Proc Natl Acad Sci U S A 2003, I00: |4439-|4444.

85. Semyanov A, Walker MC, Kullmann DM: GABA uptake regulates cortical excitability via cell type-specific tonic inhibition. Nat Neurosci 2003, 6:484-490.

86. Glykys J, Mody I: Hippocampal network hyperactivity after selective reduction of tonic inhibition in GABA $A$ receptor alpha5 subunit-deficient mice. I Neurophysiol 2006 95:2796-2807

87. Papatheodoropoulos C, Kostopoulos G: Spontaneous, low frequency (approximately 2-3 Hz) field activity generated in rat ventral hippocampal slices perfused with normal medium. Brain Res Bull 2002, 57:187-193.

88. Chrobak JJ, Buzsaki G: High-frequency oscillations in the output networks of the hippocampal-entorhinal axis of the freely behaving rat. I Neurosci 1996, 16:3056-3066.

89. Baude A, Bleasdale C, Dalezios Y, Somogyi P, Klausberger T: Immunoreactivity for the GABAA Receptor \{alpha\} I Subunit, Somatostatin and Connexin36 Distinguishes Axoaxonic, Basket, and Bistratified Interneurons of the Rat Hippocampus. Cereb Cortex 2006, I 7(9):2094-2107.

90. D'Antuono M, de Guzman P, Kano T, Avoli M: Ripple activity in the dentate gyrus of dishinibited hippocampus-entorhinal cortex slices. J Neurosci Res 2005, 80:92-103.
91. Papatheodoropoulos C: NMDA receptor-dependent high-frequency network oscillations $(100-300 \mathrm{~Hz})$ in rat hippocampal slices. Neurosci Lett 2007, 4 I 4: 197-202.

92. MacDonald RL, Rogers C], Twyman RE: Barbiturate regulation of kinetic properties of the GABAA receptor channel of mouse spinal neurones in culture. J Physiol 1989, 4I 7:483-500

93. Rho JM, Donevan SD, Rogawski MA: Direct activation of GABAA receptors by barbiturates in cultured rat hippocampal neurons. J Physiol 1996, 497:509-522.

94. Todorovic SM, Lingle C): Pharmacological properties of T-type $\mathrm{Ca2}+$ current in adult rat sensory neurons: effects of anticonvulsant and anesthetic agents. I Neurophysiol 1998, 79:240-252.

95. Lingamaneni R, Hemmings HC Jr.: Differential interaction of anaesthetics and antiepileptic drugs with neuronal $\mathrm{Na}+$ channels, $\mathrm{Ca2}+$ channels, and $\mathrm{GABA}(\mathrm{A})$ receptors. $\mathrm{Br}$ Anaesth 2003, 90:199-2II.

96. ffrench-Mullen JM, Barker JL, Rogawski MA: Calcium current block by (-)-pentobarbital, phenobarbital, and CHEB but not (+)pentobarbital in acutely isolated hippocampal CAI neurons: comparison with effects on GABA-activated $\mathrm{Cl}$ - current. Neurosci 1993, 13:321|-3221.

97. Kudrimoti HS, Barnes CA, McNaughton BL: Reactivation of hippocampal cell assemblies: effects of behavioral state, experience, and EEG dynamics. J Neurosci 1999, 19:4090-4I01.

98. Veselis RA: The EEG as a monitor of sedation: encouraging progress. J Clin Anesth 1996, 8:8IS-87S

99. Robbe D, Montgomery SM, Thome A, Rueda-Orozco PE, McNaughton BL, Buzsaki G: Cannabinoids reveal importance of spike timing coordination in hippocampal function. Nat Neurosci 2006, 9:1526-1533.

100. Gajraj RJ, Doi M, Mantzaridis H, Kenny GN: Analysis of the EEG bispectrum, auditory evoked potentials and the EEG power spectrum during repeated transitions from consciousness to unconsciousness. $\mathrm{Br}$ J Anaesth 1998, 80:46-52.

I0I. Isomura Y, Sirota A, Ozen S, Montgomery S, Mizuseki K, Henze DA, Buzsaki G: Integration and segregation of activity in entorhinal-hippocampal subregions by neocortical slow oscillations. Neuron 2006, 52:87|-882

102. Molle M, Yeshenko O, Marshall L, Sara SJ, Born J: Hippocampal sharp wave-ripples linked to slow oscillations in rat slowwave sleep. I Neurophysiol 2006, 96:62-70.

103. Buzsaki G: Two-stage model of memory trace formation: a role for "noisy" brain states. Neuroscience 1989, 3 I:55 I-570.

104. Chapouthier G, Venault P: GABA-A receptor complex and memory processes. Curr Top Med Chem 2002, 2:84I-85I.

105. Fox JE, Jefferys JG: Frequency and synchrony of tetanicallyinduced, gamma-frequency population discharges in the rat hippocampal slice: the effect of diazepam and propofol. Neurosci Lett 1998, 257:101-104.

Publish with Bio Med Central and every
scientist can read your work free of charge
"BioMed Central will be the most significant development for
disseminating the results of biomedical research in our lifetime. "
Sir Paul Nurse, Cancer Research UK
Your research papers will be:
- available free of charge to the entire biomedical community
- peer reviewed and published immediately upon acceptance
• yours - you keep the copyright
Submit your manuscript here:
http://www.biomedcentral.com/info/publishing_adv.asp

